\section{Cervical intraepithelial neoplasia: Clinical update and implications for nursing practice}

\section{by Karen Tamlyn-Leaman and Linda S. Nugent}

\section{Abstract}

This paper provides an overview of the education and support needs of women with abnomal Pap smearx. Cervical intraepithelial neoplasia (CIN), risk factors for the development of cervical cancer, diagnosis by colposcopy, and treatment approaches will be presented. This background information lays a foundation for enhancing the quality of nussing care for these women.

Over the past 15 years the colposcopic examination, a diagnostic test developed for the follow-up of "abnormal" Pap smears, has become widely used, Consequently, there has been an increase in the diagnosed incidence of cervical intraepithelial neoplasia (CIN), especially in young sexually active women (Cashavelly, 1987; Demarest, 1985; Lovejoy, 1987; Lauver and Rubin, 1991). Many women have negative emotional responses to an abnormal Pap smear and the diagnosis of a precancerous lesion of the cervix (Barker, 1984; Beresford and Gervaize, 1986; Cashavelly, 1987; Lovejoy, 1987). In addition, a recent study indicated that women are missing fundamental knowledge about this phase of the disease trajectory (Nugent and Tamlyn-Leaman, 1992a). In order to offer these woman the support and education they need, nurses need to know about early cervical cell changes, their implications for health, and the myriad of responses women display.

\section{The disease process}

Cervical cancer is a progressive disease which begins as abnormal cells in the cervical cpithelium. Dysplasia is the term commonly used todescribe these initial cell changes. Precancerous or preinvasive lesions of the cervix are synonymous with dysplasia. The degree of abnormality can be rated as mild, moderate, or severe depending upon the extent to which the full thickness of the oervical epithelium is affected (Barker 1984; Cashavelly, 1987; Lovejoy,

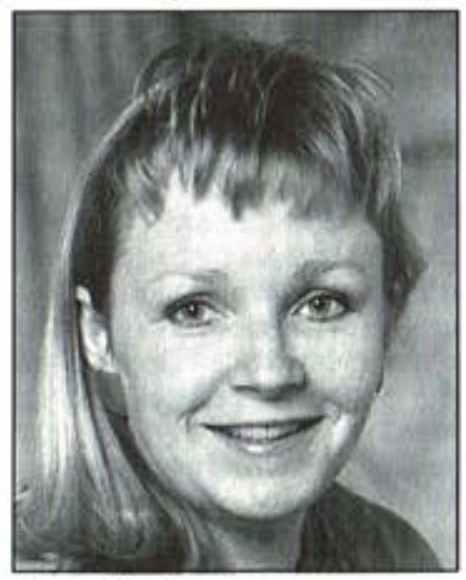

Karen Tamlyn-Leaman

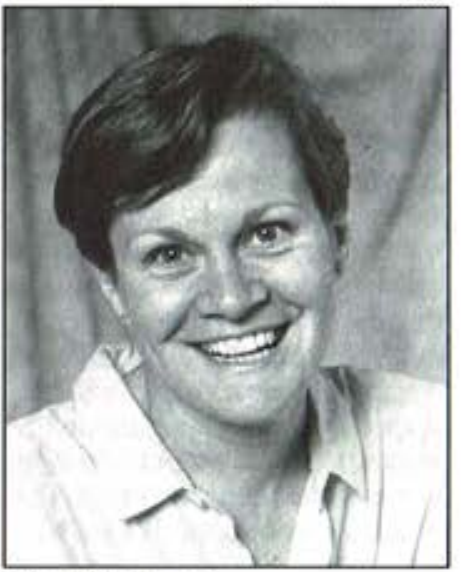

Linda S. Nugent
1987). According to the CIN classification system, mild dysplasia is classified as CIN 1 and involves less than one-third of the epithelium. Moderatc dysplasia or CIN 2, describes lesions in which one-third to two-thirds of the epithelium is involved; and CIN 3 involves the full thickness of the cervical epithelium. CIN 3 may be classified as severe dysplasia including carcinoma in situ (CIS). Once the abnormal changes extend beyond the basement membrane of the cervical epithelium, there is invasive cancer (see Figure One).

These precanoerous lesions of the cervix may regress, persist, or progress to more severe dysplasia, CIS or invasive canoer (Cashavelly, 1987; L ovejoy, 1987; Otte, 1991). It is generally accepted that the higher the grade of CIN, the greater the likelihood of progression (Baker, 1984; Cashavelly, 1987; Lovejoy, 1987; Otte, 1991).

\section{Risk factors for cervical cancer}

Cervical cancer is considered a sexually transmitted disease (Baldwin and Goodwin, 1985; Ginsberg, 1991). Initial sexual contact before 20years of age, multiple sexual partners, and relations with male partners who have had multiple scxual partners are risk factors for developing this disease. Cigarette smoking and a history of genital infections, such as herpes, human papillomavirus (HPV), or chlamydia are other risk factors (Baldwin and

Figure One. Schematic representation of precancerous cervical lesions. CIN, cervical intraepithelial neoplasia.

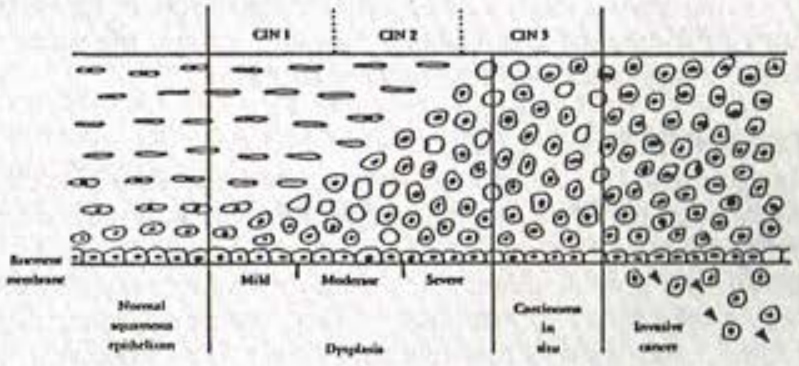

(From Novak's textbook of gynecology (p. 310) by H.W. Jones and G.S. Jones, 1981, Baltimore: Williams and Wilkins. Copyright 1981 by The Williams and Wilkins Co., Baltimore. Reprinted by permission. )

NÉOPLASIE INTRA-ÉPITHÉLIALE DU COL UTÉRIN: MISE À JOUR CLINIQUE ET RÉPERCUSSIONS SUR LA PRATIQUE CLINIQUE

\section{ABRÉGÉ}

Cet article offre un aperçu des besoins qui se font sentir dans les domaines de l'éducation et du soutien chez les femmes présentant des frottis vaginaux anormaux. Il présente la néoplasic intra-épithéliale du col utérin, les facteurs de risque de développement de cancers du col utérin, le diagnostic par colposcopie et les differentes approches de traitement. Cette information générale bátit la fondation a partir de laquelle on peut améliorer les soins infirmiers dispensés à ces patientes.

Karen Tamlyn-Leaman, RN, MN, is an assistant professor at the University of New Brunswick, Faculty of Nursing, in Fredericton, New Brunswick. Linda S. Nugent, RN, MScN, is an associate professor, at the University of New Brunswick, Faculty of Nursing, in Saint John, New Brunswick. 
Goodwin, 1985; Cashavelly, 1987; Deitch and Smith, 1983; Ginsberg, 1991; Lovejoy, 1987; Otte, 1991). Nicotine has been isolated in cervical'mucus and is purported to lower the immunologic defense of the cervix (Hellberg, Nilsson, Haley, Hoffman, and Wynder, 1988).

HPV is a sexually transmitted disease which produces condyloma acuminatum or "venereal warts" (Azocar et al., 1990; Barker, 1984; Cashavelly, 1987; Deitch and Smith, 1983). Although more than 60 types of HPV have been isolated, only certain types $(6,11,16,18,33)$ have been specifically linked to precancerous lesions of the cervix (Azocar et al. 1990; Cashavelly, 1987; Deitch and Smith, 1983; Lovejoy, 1987). The initial colposcopy visit may be the first time women learn they have HPV. They are usually told they have "been infected with a virus" or have "venereal warts". Understandably, this may evoke many feelings including shock, anger, guilt or embarrassment.

\section{Colposcopic examination}

When a cervical abnormality is detected by Pap screening, a colposcopy is done to diagnose the nature and extent of the abnormality. The colposcope provides a three-dimensional magnified view of the cervix, vulva and vagina. During the colposcopic examination, the cervix is swabbed with vinegar which accentuates any abnormal area(s) found in neoplasia by turning them white (Cashavelly, 1987). In addition to the colour tone change, the differentiation between normal and abnormal area(s) is based on vascular patterns, intercapillary distance, surface contour, and clarity of demarcation of any apparent lesions (Wright and Lickrish, 1989). With the enhanced visualization provided by the colposcope, a directed biopsy of any abnormal area(s) on the cervix is taken for diagnosis. Depending on the nature of the woman's problem, the examination may also include the vulva. The procedure usually takes 10 to 20 minutes to complete.

\section{Treatments for CIN}

The treatment for CIN varies depending upon the extent of the lesion, the woman's age, her desire for additional children, how likely she is to comply with follow-up instructions, and other medical and surgical disease (Miller et al., 1991). The goal of treatment is to destroy the abnormal area(s). Treatment approaches include laser surgery, conization, electrocautery, cryosurgery, cone biopsy or hysterectony (Barker, 1984; Cashavelly, 1987; Miller et al., 1991; Otte, 1991; Patterson, 1983). Oftentimes treatment can be performed on an outpatient basis.

Laser surgery, the newest form of treatment for CIN, is frequently used. The laser emitsa beam of highenergy which is directedat the area of dysplasia. The beam raises the tissue temperature resulting in vaporization, cell shrinkage and tissue loss (Brown, 1985). The laser is mounted on the colposcope which enables the colposcopist precise control of the laser beam. One of the advantages of laser treatment is that little unaffected tissue is removed along with the abnormal area (Otte, 1991).

Electrocautery destroys the abnormal cervical epithelium by burning the tissue, whereas cryosurgery destroys the abnormal area by freczing (Cashavelly, 1987; Otte, 1991). A hysterectomy may be necessary for a woman with severe CIN or CIS, especially if she does not wish to maintain her fertility.

Conization involves the removal of a cone-shaped piece of cervical tissue. It can be used as either a diagnostic or therapeutic procedure. Prior to the use of colposcopy, women had to undergo conization for definitive diagnosis of cervical lesions. Today, a diagnostic conization is only necessary in situations in which the entire lesion cannot be visualized by colposcopy and when there is a discrepancy between the cytologic report and histologicappearance (Otte, 1991; Patterson, 1983). A therapeutic conization may be performed to remove the area of the cervix that contains the abnormal epithelium (Cashavelly, 1987; Otte, 1991; Patterson, 1983).

Although treatment of CIN may be curative, recurrence rates of zero to $23 \%$ have been reported (Lovejoy, 1987). As the probability of discase progression is high, proper follow-upand treatment is essential. The prognosis for CIN and CIS is good if proper treatment is received to prevent the development of invasive cancer of the cervix (Cashavelly, 1987).

\section{Nursing implications}

Through their teaching and counselling roles, nurses have a critical role to play in the prevention of invasive cervical cancer. Opportunities to establish good nurse-client relationships are afforded by womens' repeat visits to clinic for follow-up and treatment. Within this relationship much valuable information and support can be provided.

\section{Teaching}

Recognizing the busy setting of colposcopy clinics, nurses need a deliberate plan if they are to provide the best quality of care. To avoid unnecessary repetition, the plan should vary by the first-time versus repeat visit yet allow for individual concerns. First-time colposcopy clients' concerns usually centre around the meaning of abnormal Pap results (Barsevick and Lauver, 1990; Lauver and Rubin, 1991; Nugent and Tamlyn-Leaman, 1992a) and the nature of the colposcopy procedure (Barsevick and Lauver, 1990; Nugent and Tamlyn-Leaman, 1992a).

Before responding to questions about the meaning of Pap results, an assessment of the woman's knowledge about female reproductive anatomy should be carried out. A recent study indicated that $40 \%$ of 149 first-time colposcopy clients did not know the location of their cervix (Nugent and Tamlyn-Leaman, 1992a). When explaining dysplasia, nurses need to reinforce the progressive nature of undetected and untreated CIN. Equipped with this information, women are better prepared to make informed decisions regarding compliance with colposcopy, necessary treatment and follow-up.

Studies (Barsevick and Lauver, 1990; Nugent and Tamlyn-Leaman, 1992a) have outlined information needs relative to the colposcopy procedure. Teaching about the exam should include a description of the colposcope, an explanation of its main purpose and an indication that it does not enter the vagina. As well, nurses need to emphasize that a biopsy is usually a routine part of the exam. From the authors' clinical experience, it is apparent that women who are unprepared for the possibility of a biopsy have unnecessary concerns about the seriousness of their health problem.

Young sexually active women are an especially important target group for health teaching because there has been an increase in the diagnosed incidence of CIN in these women (Cashavelly, 1987; Demarest, 1985; Lovejoy, 1987; Lauver and Rubin, 1991). In particular, young women need tobe made aware that choices made today with respect to sexual activity and smoking can increase their risk for developing cervical cancer (Cashavelly, 1987). Nurses also need to advise young women of their responsibility in attending for regular Pap screening. Many young women do not believe that regular Pap smear screening isnecessary as they consider themselves too young todevelop cancer of the cervix. (Deitch and Smith, 1983). However, the cervical epithelial cells of adolescents may be particularly sensitive to carcinogens because of the increased mitotic activity during this period (Baldwin and Goodwin, 1985; Cashavelly, 1987; Lovejoy, 1987). Therefore, nurses should instruct women to begin a Pap screening program at age 18 or when they become sexually active, whichever comes first (Tombes, 1991).

\section{Counselling}

Nurses must recognize that women experience anxiety in response to receiving news of an abnormal Pap result, the need for colposcopy, and having the colposcopy procedure. Nugent and Tamlyn-Leaman (1992b) identified that younger women with concurrent stressors in their lives and less knowledge about the experience are more anxious. Worry or concern about the results, expressed as not knowing what is wrong, experiencing a change in health status, or entertaining concern about future health status also contribute to the anxiety (Nugent and Tamlyn-Leaman, 1992b). Sometimes these emotional responses are associated with a fear of cancer, concern about reproductive/sexual functioning, or embarrassment related to contracting a sexually transmitted disease (Beresford and Gervaize, 1986; Ginsberg, 1991).

As indicated earlier, women may have negative emotional responses to the diagnosis of HPV. Nurses can provide women with the opportunity to share these feelings and other concerns surrounding the stigma of a sexually transmitted disease. Women need to know the sexual transmission "...is not an immediate thing. It can take quite a long time from exposure to onset..." (Gervaize and Beresford, 1984, p.42). Such knowledge can "alleviate qualms about current sexual relationships" (Gervaize and Beresford, 1984, p.42).

In addressing women's anxiety, nurses can outline the types of information described above. They can also give support by listening to women's concerns 
regarding any changes in their health status. The fact that CIN is usually asymptomatic (Otte, 1991) needs to be reinforoed. Nurses' familiarity with symptoms of cervical cancer can enable them to help these women toconsider unrelated symptoms realistically. According to Otte (1991) women with cervical cancer often have a watery or bloody vaginal discharge, and may experience pelvic, flank, or leg pain as late symptoms.

\section{References}

1.Azocar, J,AbadS. MJ., Acosta,H,Hernandę, R,, Gallegos, M. Pifano, E., Btanch, R., and Kramar, A. (1990). Prevalenoe of cervical dysplasia and HPV infection acoording to sexual behaviour. International Journal of Cancer, 45, 622-625.

2. Baldwin, K. and Goodwin, K. (1985). The Papanicolaou smear. Journal of Nurse-Midwifery, 30, 327-332.

3. Barker, F. (1984). An abnormal Pap smear: What does it really mean? Journal of Medical Technology, 1, 905-908.

4. Barsevick, A.M. and Lauver, D. (1990) Women's informational needs about colposcopy. Image: Journal of Nursing Scholarship, 22, 23-26.

5. Beresford, J.M. and Gervaize, P.A. (1986). The emotional impact of abnormal pap snears on patients referred for colposcopy. Colposcopy and Gynecological Laser Surgery, 2, 83-87.

6. Brown, N.L_ (1985). Carbon dioxide lasers: Advantages and disadvantages in GYN surgery. American Operating Room Nurses Journal, 42, 53-57.

7. Cashavelly, B.J. (1987). Cervical dysplasia. Cancer Nursing, 10, 199-206. 8. Deitch, K. and Smith, J. (1983). Cervical dysplasia and condylomata acuminata in young women. Journal of Obstetric, Gynecologic, and Neonatal Nursing, 20, 155-158.

9. Demarest, C.B. (1985). Getting the most from the Pap smear. Patient Care, $19(4), 63-86$.

10. Gervaize, P., and Beresford, J. (1984). Outpatient gynecological laser therapy: Patient concerns and how to deal with them. Canadian Operating Room Nursing Journal, 2(5), 34-43.

11. Ginsberg, C. (1991). Exfoliative cytologic screening: The Papanicoulaou test. Journal of Obstetric, Gynecologic, and Neonatal Nursing, 20, 39-46.

12. Hellberg, D. Nilsson, S. Haley, N., Hoffman, D. and Wynder, E. (1988). Smoking and cervical intraepithelial neoplasia: Nicotine and cotinine in serum

\section{Summary}

From the above owerview of CIN it is apparent that nurses can play a vital role in helping women deal with this health problem. To be effective in their role, nurses need to be knowledgeable about CIN, itsdiagnosis and treatment, and sensitive to women's psychosocial concerns.

\section{Cervical cancer screening and detection - Patient education}

\section{The woman with an abnormal Pap test}

and cervical mucus in smokers and nonsmokers. American Journal of Obstetrics and Gynecology, 158, 910-913.

13. Jones, H.W. and Jones G.S. (1981). Novak's textbook of gynecology. Baltimore: Williams and Wilkins.

14. Lauver, D. and Rubin, M. (1991). Women's concerns about abnormal papanicolaou test results. Journal of Obstetric, Gynecologic, and Neonatal Nursing, 20, 154-159.

15. Lovejoy, N. (1987) Precancerous lesions of the cervix: Personal risk factors. Cancer Nursing, 10(1), 2-14.

16. Miller, A., Anderson, G., Brisson, J., Laidlaw, J., LePitre, N., Malcolmson, P., Mirwaldt, P., Stuart, G., and Sullivan, W. (1991). Report of a national workshop on screening for cancer of the cervix. Canadian Medical Association Journal, 145(10), 1301-1325.

17. Nugent, L.S. and Tamlyn-Leaman, K. (1992a). the colposcopy experience: What do women know? Journal of Advanced Nursing, 17, 514-520.

18. Nugent, L. S. and Tamlyn-Leaman, K. (1992b). Anxiety and the colposcopy experience. Unpublished manuscript.

19. Otte, D.M. (1991). Gynecologic cancers. In S.I. Groenwald, M.H. Frogge, M. Goodman, C.H. Yarbo (Eds.), Cancer nursing: Principles and practice (Second Edition) (pp. 845-888). Boston: Jones and Bartlett.

20. Patterson, J. (1983). Colposcopy. Journal of Obstetric, Gynecologic, and Neonatal Nursing, 12, 11-15.

21. Tombes, M. (1991). Gynecological malignancies. In S. Baird, M. Donehower, V. Stalsbroten, and T. Ades (eds.). A cancer source book for nurses (Sixth Edition) (pp. 228-241) Atlanta: American Cancer Society.

22. Wright, CV. and Lickrish, G.M. (ock). Basicand advancedool poscopy:A practical handbook for diagnosis and treatment. Komoka, ON: Biomodical Communications
1. The results of your Pap test indicate that the cells from your cervix are

2. The cervix is the medical term for the lower part of your which the doctor can see when he looks into your vagina.

3 . We do not believe that you have at this time.

4. This problem requires further tests to see if is needed to prevent cancer from developing.

5. You will be referred to a specially trained gynecologist for a procedure called

6. To prepare for colposcopy, for a period of hours before your appointment, prevent the dislodging of cells from your cervix by avoiding the insertion of anything into your vagina which could rub against or stick to the cervix. This includes douching, vaginal medications or creams, tampons, sexual intercourse. You may have a tub bath or shower.

7. The colposcope is similar to a

8. The colposcope does not touch or your body.

9. The gynecologist will insert a into your vagina and repeat your Pap test. 10. He will then look through the colposcope which will make the cervix appear he can see if it appears normal or abnormal. 11. This examination itself takes approximately minutes.

12. To help you feel more relaxed during the examination, breathe and deeply.

13. The doctor will swab your cervix with mild acetic acid which is another name for

14. Any abnormal cells will temporarily change in colour from pink to

15. If a white area appears, the doctor will take one or more small samples of tissue. This is known as a

16. During a biopsy you may experience mild

17. After a biopsy slight may occur for a few days.

18. You may wear a minipad, but avoid using tampons or having

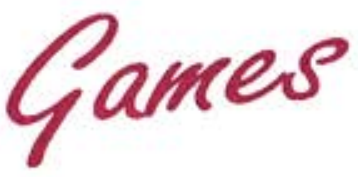
ala 40 ares 19. All three parts of this examination, the Pap test, colposcopy examination and biopsy enable the doctor to decide if is required.

20. You will be notified of your test results in approximately weeks.

21. If your test results indicate that treatment or further is required, you will be instructed to return to the gynecologist for another appointment.

22. If your test results are you will return toyour family doctor for your regular Pap tests.

Prepared by Miriam R. Hills, Coordinator Cancer Program, Continuing Medical and Continuing Nursing Education, University of Saskatchewan, Saskatoon, Saskatchewan. Thanks to Dr. D.R. Popkin, Acting Dean of the College of Medicine, University of Saskatchewan, for reviewing this material.

Answers are found on page 131 